\title{
Novel approaches to improving growth of pasture legumes at low phosphorus levels
}

\author{
S.N. NICHOLS and J.R. CRUSH \\ AgResearch, Ruakura Research Centre, Private Bag 3123, Hamilton \\ shirley.nichols@agresearch.co.nz
}

\begin{abstract}
Strategies to reduce the economic and environmental costs of phosphate $(\mathrm{P})$ fertiliser use in mixed pastures through plant breeding are focussed on inefficiencies in the legume component. One approach is breeding within white clover for root systems with improved $\mathrm{P}$ acquisition properties. Selection for root length per unit root weight (specific root length, SRL) showed that higher SRL plants could retain more biomass in the above ground fraction with decreasing soil $\mathrm{P}$, whereas plants with lower SRL diverted more biomass to roots. Back cross $1\left(\mathrm{BC}_{1}\right)$ generation interspecific hybrids between white clover and a wild relative, Trifolium uniflorum L., may possess additional root traits influencing $\mathrm{P}$ acquisition. In glasshouse experiments, some $T$. repens $\times T$. uniflorum hybrids, back-crossed to white clover, also exhibited higher shoot dry weight than their white clover cultivar parents at low nutrient supply levels and low to intermediate soil Olsen P. This, combined with low internal $\mathrm{P}$ concentrations, suggests some $\mathrm{BC}_{1}$ hybrids may be more tolerant of low soil $\mathrm{P}$ than white clover. Differences in both $\mathrm{P}$ acquisition ability and internal $\mathrm{P}$ use efficiency may contribute to the observed yield differences. There are good prospects for delivery of new-generation clover cultivars with improved phosphate use efficiency to New Zealand farmers.
\end{abstract}

Keywords: phosphorus, white clover, Trifolium uniflorum, interspecific hybridisation, root morphology, P-efficiency

\section{Introduction}

Legumes are an important component of temperate grassland systems, through their contribution to feed quality, seasonal growth and nitrogen $(\mathrm{N})$ fixation. Phosphorus (P) is essential for legume production, and phosphate fertiliser is a major cost in most New Zealand farm budgets. The environmental impacts of $\mathrm{P}$ losses on surface water quality (Monaghan et al. 2007), and the footprint costs of transporting phosphate rock to New Zealand (Ledgard et al. 2011) are increasing concerns. In addition, phosphate rock is a finite resource for which there is an increasing demand worldwide (Lott et al. 2011), and security of future supply of high quality rock is likely to become an important issue.

The development of P-efficient forage legumes that allowed reduced $\mathrm{P}$ fertiliser inputs would yield significant economic and environmental benefits. New Zealand's grass/clover pastures have an in-built inefficiency in that grasses compete very strongly with white clover (Trifolium repens L.) for P, and much more superphosphate is needed to grow white clover with grasses than on its own (Mouat \& Walker 1959). Although earlier research suggested it should be possible to breed more P-efficient white clover cultivars, attempts to demonstrate improved P-use efficiency in the field were unsuccessful (Caradus \& Dunn 2000).

This paper describes some of our current work on P-efficiency in white clover, which focusses on two areas - improved P acquisition and improved internal efficiency. Interspecific hybridisation is a new approach, introducing new genes and traits into the white clover gene pool. We are studying hybrids between white clover and a wild relative Trifolium uniflorum L. to determine whether P-efficiency or tolerance of low soil $\mathrm{P}$ can be improved through hybridisation.

\section{Methods}

\section{White clover root selections}

A total of 845 plants from a polycross of MiddleEastern material were grown in hydroponic culture and digital images of the root systems were analysed using WinRhizo ${ }^{\mathrm{TM}}$ software. Stolon tip cuttings were taken from genotypes selected for high or low specific root length (SRL, root length/unit root dry weight) with 10 genotypes in each group, and grown in $15 \mathrm{~cm}$ pots containing $0.9 \mathrm{~kg}$ of dry Horotiu sandy loam subsoil collected from a dairy pasture. $\mathrm{K}_{2} \mathrm{SO}_{4}$ and $\mathrm{MgO}$ were added to bring levels of $\mathrm{K}$ and $\mathrm{Mg}$ up to target values for dairy farming on the soil type. The soil had been premixed with $\mathrm{CaHPO}_{4}$ to give Olsen $\mathrm{P}$ values of 6 , 9, 14 and $20 \mathrm{mg} \mathrm{P} / \mathrm{kg}$ soil. There were three clonal replicates of each plant genotype at every $\mathrm{P}$ level in a row/column design, inoculated with a commercial rhizobium inoculant. Plants were harvested after 13 weeks, and shoots and roots separated, dried at $70^{\circ} \mathrm{C}$ for $>24$ hours, and weighed. 


\section{Interspecific hybrids}

The hybrid clover entries were backcross $1\left(\mathrm{BC}_{1}\right)$ families, created by crossing $\mathrm{F}_{1} T$. repens $\times T$. uniflorum hybrids to one or both of two contrasting white clover parental cultivars ('Grasslands Kopu II' and 'Crusader'), to which they are compared. In some cases, T. uniflorum accessions were also included. There were ten replicates of each clover entry. Experiments were conducted in a glasshouse at AgResearch, Ruakura Research Centre. At harvest, plants were separated into roots and shoots; or roots, stolons and leaves. Total macronutrients, or $\mathrm{P}$ concentrations only, were analysed in shoot or leaf material. Leaf inorganic $\mathrm{P}\left(\mathrm{P}_{\mathrm{i}}\right)$ was also measured in Experiment 2, and calculated as a fraction of total leaf P.

Experiment 1 - Plants were grown in $1 \mathrm{~m}$ deep $\times$ $150 \mathrm{~mm}$ diameter tubes of sand culture. A low ionic strength (LIS) nutrient solution (Blamey et al. 1991) was applied to all tubes five times per week, and plants were harvested after 8 months of growth. Dry weight data were natural $\log$ transformed, and analysed by ANOVA in Minitab. Macronutrient data was analysed by REML in Genstat.

Experiment 2 - This was conducted in 1.24 litre pots of sand culture. Three nutrient treatments were applied three times per week - a highly concentrated Long Ashton solution, LIS, and half-strength LIS. Plants were harvested after 4.5 months of growth. Data were analysed using linear mixed modelling (LMM) with REML in Genstat. Hybrid families are compared with their respective white clover cultivar parent.

Experiment 3 - This pot experiment used the same soil and basal nutrients as the SRL experiment, with $\mathrm{CaHPO}_{4}$ mixed through each pot to provide Olsen $\mathrm{P}$ levels of $6,7,9,14$, and $20 \mathrm{mg} \mathrm{P} / \mathrm{kg}$ soil. Plants were harvested after 13 weeks, and root morphological traits were measured on the first lateral root from each plant, using WinRhizo ${ }^{\mathrm{TM}}$ software. Data were analysed using LMM with REML in Genstat.

\section{Results and Discussion}

\section{White clover root selections}

Root morphology (diameters, lengths) and architecture (branching patterns) can play a significant role in the acquisition of nutrients, as demonstrated by the competition between ryegrass and white clover for soil P (Jackman \& Mouat 1972). Our approach here was to select for SRL in white clover, in order to develop populations which would be more competitive for $\mathrm{P}$ in a mixed sward. Heritability for root traits in white clover is high, and selection has been shown to bring about changes in root morphology (Caradus \& Woodfield 1998).

Root:shoot ratios increased with decreasing soil $\mathrm{P}$, due to reallocation of biomass to roots for acquisition

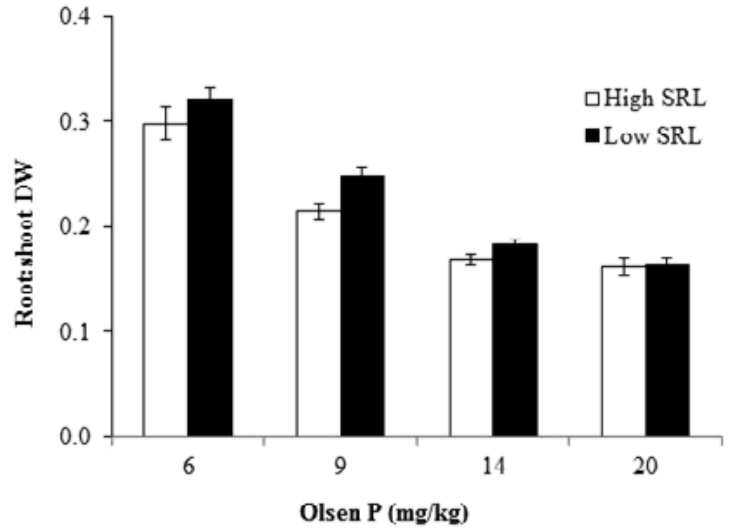

Figure 1 Mean root:shoot dry weight (DW) ratios of high and low specific root length (SRL) white clover selections at four soil Olsen $\mathrm{P}$ levels.

of the limiting resource (Figure 1). However the ratios increased significantly $(\mathrm{P}<0.001)$ less in high SRL selections as their finer roots could acquire more $\mathrm{P}$, limiting the need to reallocate biomass to roots. This enabled plants with fine roots to maintain up to $20 \%$ higher shoot production. There was substantial variation in P response within both SRL groups, and a re-examination of the roots suggested that differences in root hair length and density might explain some of this variation. Root hairs are a relatively effective way for plants to increase root surface area and P uptake. For white clover, selecting for root hair length can increase the volume of the soil explored by roots, $\mathrm{P}$ absorption and growth (Caradus 1979, 1981). The next step is to combine high SRL with long, dense root hairs.

\section{Interspecific hybrids}

In $1 \mathrm{~m}$ deep sand tubes, shoot DW of Kopu II $\mathrm{BC}_{1}$ was 10 times greater than 'Kopu II'; Crusader $\mathrm{BC}_{1}$ was 24 times greater than 'Crusader', and the T. uniflorum accessions were up to 19 times greater than white clover (Figure 2). This contradicted the expected pattern. Under field conditions, Nichols et al. (2014b) observed significantly lower dry matter $(\mathrm{DM})$ production in $T$. repens $\times$ T. uniflorum $\mathrm{BC}_{1}$ and $\mathrm{BC}_{2}$ hybrids compared with white clover, and in T. uniflorum compared with hybrid families as well as white clover. Although the nutrient solution used here has been used successfully in similar experiments with perennial ryegrass, there appear to be species differences in the adequacy of nutrient supply, most likely driven by differences in root traits which affect $\mathrm{P}$ acquisition.

Most shoot mineral concentrations were adequate for white clover growth in the clover entries that were analysed, but P concentrations (Figure 2) were well below the published (McNaught 1970) critical level of $3400 \mathrm{mg} / \mathrm{kg}$. Given the differences in DW production, 


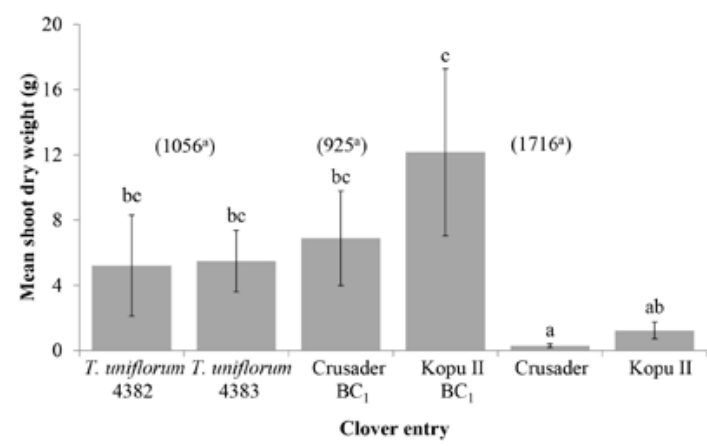

Figure 2 Mean shoot dry weight of 8-month-old plants of T. uniflorum, Crusader $\mathrm{BC}_{1}$, Kopu II $\mathrm{BC}_{1}$, 'Crusader' and 'Kopu II', in sand culture. Values in brackets are back-transformed mean shoot $\mathrm{P}$ concentrations $(\mathrm{mg} / \mathrm{kg})$. Means with the same letter are not significantly different at the $5 \%$ level.

this suggested that $T$. repens $\times$ T. uniflorum hybrids might be more tolerant than white clover of low external $\mathrm{P}$ concentrations. There is little information available on the edaphic adaptations of T. uniflorum.

The sand culture pot experiment confirmed these results, but also showed that not all hybrids are equal. In the LIS solution, three of the four hybrid families were significantly larger than their parental white clover cultivar. This dropped to two out of four in the more dilute $1 / 2$ LIS solution (Table 1 ). Shoot DWs of the hybrids were up to five times larger than their white clover parents. The effect of decreasing nutrient solution strength on shoot DW also varied among hybrid families (Table 2).

The shoot $\mathrm{P}$ concentration of Kopu II $\mathrm{BC}_{1} \mathrm{~B}$ was significantly lower than 'Kopu II' and Kopu II BC A (Table 1), indicating an ability to grow at lower internal P concentrations. This entry was also the least affected by decreasing nutrient solution strength (Table
2), and had the highest shoot DWs in the LIS and $1 / 2$ LIS treatments. Shoot inorganic $\mathrm{P}\left(\mathrm{P}_{\mathrm{i}}\right)$ concentration in Kopu II BC 1 B was also significantly lower than 'Kopu II' and Kopu II $\mathrm{BC}_{1}$ A, as was the fraction of the total $\mathrm{P}$ pool in inorganic form (Table 1). A high proportion of $\mathrm{P}_{i}$ is one explanation for white clover's high P requirement (Hart \& Jessop 1983). The lower $P_{i}$ fraction of one hybrid may, therefore, have contributed to differences in growth at low external P supply.

The results from sand culture were confirmed by the pot experiment using soil. At Olsen P $20 \mathrm{mg} / \mathrm{kg}$, shoot DW of Kopu II $\mathrm{BC}_{1} \mathrm{C}$ was $35 \%$ greater than its white clover parent and a second hybrid family. Shoot $\mathrm{P}$ concentrations did not differ among the clover entries, so internal P use efficiency did not differ. Meaningful comparisons of SRL between entries are difficult because of the complication of possible differences in root tissue density (Nichols 2012). However, there were differences in other root traits which may have influenced growth through increased $\mathrm{P}$ acquisition. In Kopu II $\mathrm{BC}_{1} \mathrm{C}$, the root:shoot ratio was considerably higher in the lowest $\mathrm{P}$ treatment than in the other entries, and decreased sharply with increasing P supply (Figure 3). Scavenging for $P$ in low $P$ soils, and rapid shoot growth when $\mathrm{P}$ deficiency is alleviated, are valuable

Table 2 Effect of decreasing nutrient solution strength from Long Ashton to LIS, and Long Ashton to $1 / 2$ LIS, on mean shoot and root dry weight (DW) in 'Kopu II' compared with Kopu II BC 1 hybrids. LIS, low ionic strength.

\begin{tabular}{lcccc}
\hline & \multicolumn{2}{c}{ Long Ashton to LIS } & \multicolumn{2}{c}{ Long Ashton to $1 / 2$ LIS } \\
\hline & Shoot DW & Root DW & Shoot DW & Root DW \\
\hline 'Kopu II' & $-87 \%$ & $-84 \%$ & $-80 \%$ & $-77 \%$ \\
Kopu II BC 1 A & $-66 \%$ & $-66 \%$ & $-83 \%$ & $-82 \%$ \\
Kopu II BC B $_{1}$ & $-53 \%$ & $-52 \%$ & $-61 \%$ & $-62 \%$ \\
\hline
\end{tabular}

Table 1 Shoot dry weight (DW), overall shoot $P$ concentration, and the overall fraction of total shoot $P$ as inorganic $P\left(P_{i}\right)$, with three nutrient treatments, for 'Kopu II' compared with Kopu II BC hybrids, and 'Crusader' compared with Crusader $\mathrm{BC}_{1}$ hybrids. LIS, low ionic strength; LA, Long Ashton. Means within columns with the same letter are not significantly different at the $5 \%$ level. Upper case letters indicate comparisons between Kopu II BC Bnd $_{1}$ rusader $\mathrm{BC}_{1}$ hybrids with the same F1 parent.

\begin{tabular}{lccccc}
\hline & & Shoot DW & & Shoot P (mg/kg) & Fraction $\mathbf{P}_{\mathrm{i}}(\%)$ \\
\hline & $1 / 2$ LIS & LIS & LA & & \\
\hline 'Kopu II' & $0.39^{\mathrm{a}}$ & $0.25^{\mathrm{a}}$ & $1.98^{\mathrm{a}}$ & $934^{\mathrm{a}}$ & $60.5^{\mathrm{a}}$ \\
Kopu II BC, A & $0.40^{\mathrm{a}}$ & $0.77^{\mathrm{b}}$ & $2.30^{\mathrm{a}}$ & $1091^{\mathrm{b}}$ & $56.9^{\mathrm{a}}$ \\
Kopu II BC, B & $1.14^{\mathrm{b}}$ & $1.36^{\mathrm{b}}$ & $2.91^{\mathrm{a}}$ & $803^{\mathrm{cA}}$ & $48.5^{\mathrm{bA}}$ \\
'Crusader' & $0.21^{\mathrm{a}}$ & $0.17^{\mathrm{a}}$ & $1.64^{\mathrm{a}}$ & & \\
Crusader BC, A & $0.46^{\mathrm{b}}$ & $0.34^{\mathrm{ab}}$ & $1.35^{\mathrm{a}}$ & & \\
Crusader BC, B & $0.22^{\mathrm{a}}$ & $0.36^{\mathrm{b}}$ & $1.96^{\mathrm{a}}$ & $931^{\mathrm{B}}$ & $58.8^{\mathrm{B}}$ \\
\hline
\end{tabular}




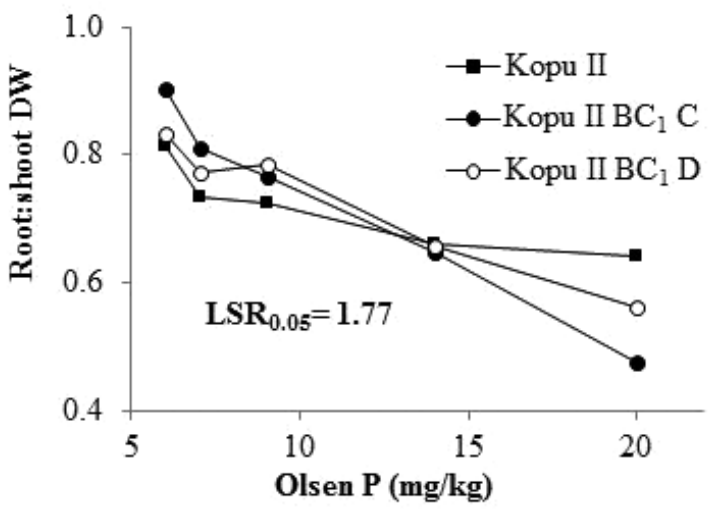

Figure 3 Mean root:shoot dry weight ratios of 'Kopu II', Kopu II BC $C_{1}$, and Kopu II BC D in soil at five Olsen P levels.

traits. This hybrid family also had significantly longer roots $(\mathrm{P}<0.001)$ with more branching (more root tips/ unit root length, $\mathrm{P}=0.015$ ) than 'Kopu II'. Differences in root traits in this hybrid have also been observed in hydroponic culture, and appear to have been inherited from the T. uniflorum parent. T. uniflorum and Kopu II $\mathrm{BC}_{1} \mathrm{~A}$ have a simpler branching pattern than white clover and Kopu II BC B, being closer to a herringbone arrangement (Nichols 2012). This architecture may be more efficient at nutrient acquisition, and indicative of adaptation to low soil fertility (Fitter 1987; Fitter \& Stickland 1991).

History shows that selection for increased internal $\mathrm{P}$ efficiency in white clover is not straightforward, because the interaction between genotype and environment clearly has a considerable impact on the expression of this trait (Caradus \& Dunn 2000). Testing "P-efficient" $T$. repens $\times T$. uniflorum hybrids in the field will, therefore, be vital. The competitiveness of ryegrass roots, which drives the high $\mathrm{P}$ fertilisation requirement of mixed pasture, suggests that $\mathrm{P}$ acquisition may be more important than internal efficiency. However, gains in utilisation may still be made by incorporating new clover genetic material through hybridisation. It is possible that both improved acquisition and internal efficiency may be operating in this material, either in combination or potentially in segregating populations. Even if only modest improvements in P efficiency are gained, the combination of this with other traits inherited from T. uniflorum, such as improved drought resistance (Nichols et al. 2014a), could provide significant benefits. Apart from the additive effect of these two traits on growth, their interaction may also be important, as soil $\mathrm{P}$ is known to influence the effects of low soil moisture on white clover growth (Singh et al. 1997). Nutrient mobility can also be affected at soil moisture levels which have no effect in themselves on plant water relations (Nye \& Tinker 1977).
The results show there are good prospects for delivery of clover cultivars with enhanced phosphate use efficiency to New Zealand farmers. This will allow a reduction in phosphate fertiliser input per unit farm production, that will improve farm profitability while reducing $\mathrm{P}$ losses to waterways.

\section{ACKNOWLEDGEMENTS}

Lily Ouyang, Kati Ruppert and Bridget Wise for technical support; Vanessa Cave and Chikako van Koten for statistical assistance. This work was funded by MBIE (contract C02X0810), DairyNZ (contract FD617), and the Pastoral 21 Research Programme (a collaborative venture between DairyNZ, Fonterra, Dairy Companies Association of New Zealand, Beef + Lamb NZ and MBIE).

\section{REFERENCES}

Blamey, F.P.C.; Edmeades, D.C.; Asher, C.J.; Edwards, D.G.; Wheeler, D.M. 1991. Evaluation of solution culture techniques for studying aluminium toxicity in plants. pp. 905-912. In: Plant-soil interactions at low pH. Eds. Wright, R. J.; Baligar, V. C.; Murrmann, R. P. Kluwer Academic Press, Dordrecht.

Caradus, J.R. 1979. Selection for root hair length in white clover (Trifolium repens L.). Euphytica 28: 489-494.

Caradus, J.R. 1981. Effect of root hair length on white clover growth over a range of soil phosphorus levels. New Zealand Journal of Agricultural Research 24: 353-358.

Caradus, J.R.; Dunn, A. 2000. Adaptation to low fertility hill country of white clover lines selected for differences in response to phosphorus. New Zealand Journal of Agricultural Research 43: 63-69.

Caradus, J.R.; Woodfield, D.R. 1998. Genetic control of adaptive root characteristics in white clover. Plant and Soil 200: 63-69.

Fitter, A.H. 1987. An architectural approach to the comparative ecology of plant root systems. New Phytologist 106 (Suppl.): 61-77.

Fitter, A.H.; Stickland, T.R. 1991. Architectural analysis of plant root systems 2 . Influence of nutrient supply on architecture in contrasting plant species. New Phytologist 118: 383-389.

Hart, A.L.; Jessop, D. 1983. Phosphorus fractions in trifoliate leaves of white clover and lotus at various levels of phosphorus supply. New Zealand Journal of Agricultural Research 26: 357-361.

Jackman, R.H.; Mouat, M.C.H. 1972. Competition between grass and clover for phosphate. II. Effect of root activity, efficiency of response to phosphate, and soil moisture. New Zealand Journal of Agricultural Research 15: 667-675. 
Ledgard, S.F.; Boyes, M.; Brentrup, F. 2011. Life cycle assessment of local and imported fertilisers used on New Zealand farms. pp. 1-11. In: Occasional Report 24. Eds. Currie, L.D.; Christensen, C.L. Fertilizer and Lime Research Centre, Massey University, Palmerston North.

Lott, J.N.A.; Kolasa, J.; Batten, G.D.; Campbell, L.C. 2011. The critical role of phosphorus in world production of cereal grains and legume seeds. Food Security 3: 451-462.

McNaught, K.J. 1970. Diagnosis of mineral deficiencies in grass-legume pastures by plant analysis. pp. 334-338. In: Proceedings of the XIth International Grassland Congress.

Monaghan, R.M.; Hedley, M.J.; Di, H.J.; McDowell, R.W.; Cameron, K.C.; Ledgard, S.F. 2007. Nutrient management in New Zealand pastures - recent developments and future issues. New Zealand Journal of Agricultural Research 50: 181-201.

Mouat, M.C.H.; Walker, T.W. 1959. Competition for nutrients between grasses and white clover. I. Effect of grass species and nitrogen supply. Plant and Soil 11: $30-40$.
Nichols, S.N. 2012. Introgression of root and shoot characteristics in Trifolium repens $\times$ Trifolium uniflorum interspecific hybrids. $\mathrm{PhD}$. thesis. Lincoln University, New Zealand. http://hdl.handle. net/10182/5091

Nichols, S.N.; Hofmann, R.W.; Williams, W.M. 2014a. Drought resistance of Trifolium repens $\times$ Trifolium uniflorum interspecific hybrids. Crop and Pasture Science: http://dx.doi.org/10.1071/CP14067

Nichols, S.N.; Hofmann, R.W.; Williams, W.M. 2014 b. The effect of interspecific hybridisation with Trifolium uniflorum on key white clover characteristics. Field Crops Research 161: 107-117.

Nye, P.H.; Tinker, P.B. 1977. Solute movement in the soil-root system. University of California Press, Berkeley. 342 pp.

Singh, D.K.; Sale, P.W.G.; McKenzie, B.M. 1997. Water relations of white clover (Trifolium repens L.) in a drying soil, as a function of phosphorus supply and defoliation frequency. Australian Journal of Agricultural Research 48: 675-682. 